\title{
"Between Myth and Cure" Group Experience in Narrative Medicine with Neurological Patients
}

\author{
Simona Ghedin ${ }^{1}$, Floriana Caccamo ${ }^{2 凶}$, Francesca Vannini ${ }^{1}$, Maria Rosaria Stabile ${ }^{1}$, \\ Luca Caldironi ${ }^{3}$, Francesca Meneghello ${ }^{1}$, \& Cristina Marogna ${ }^{2}$
}

\begin{abstract}
This research considers the observation of certain parameters within groups formed by patients affected by multiple sclerosis. A music/art therapist and a psychologist/psychotherapist at a neuro-rehabilitation structure in Venice led the groups. Our goal is to assess how the perception of the history of disease can change in patients by using myth and expressive-narrative workshops as a means of transformation. The following instruments were administered at the beginning, during, and at the end of the treatment: SCL-90-R, TAS-20, FAT.A.S.-G, and CGQ. Results show a change in patients' perceptions of themselves, both with respect to their disease and to other people. Therefore, myths and their narration appear to be a possible resource that can promote mental transformation processes in an institutional neuro-rehabilitative context.
\end{abstract}

Keywords: neurological patient, myth, group psychotherapy

\section{"Between Myth and Cure"}

Group Experience in Narrative Medicine with Neurological Patients.

Multiple sclerosis (MS) is a chronic neurological disease that implies serious physical, cognitive, and emotional consequences. The symptoms that manifest in patients are varied and may include diminished mobility, sensory disorders, chronic pain, fatigue, and cognitive deficits (Senders, Wahbeh, Spain \& Shinto, 2012). In addition, MS patients typically describe high levels of stress regardless of physical disability (Buelow, 1991; Chalk, 2007; Counte, Bieliauskas \& Pavlou, 1983) and are at risk of developing stress-related disorders such as anxie

\footnotetext{
${ }^{1}$ IRCCS, Foundation Hospital San Camillo, Venice, Italy. ${ }^{2}$ Department of Philosophy, Sociology, Pedagogy and Applied Psychology (FISSPA), Padua, Italy. ${ }^{3}$ Psychoanalytic Italian Society.

Correspondence concerning this article should be addressed to Floriana Caccamo. Dipartimento di Filosofia, Sociologia, Pedagogia e Psicologia Applicata, Università di Padova, Via Venezia, 8. E-mail: florianacaccamo@virgilio.it
}

ty (prevalence during life: 25\%) and depression (range from 34 to 50\%; Korostil \& Feinstein, 2007; Patten, Fridhandler, Beck \& Metz, 2003).

In the framework of this pathology, social support and good interpersonal relationships have been shown to reduce the risk of depression and to increase the overall quality of life (Schwartz \& Frohner, 2005). However, patients affected by MS may present the alteration of specific cognitive functions and social skills that are essential in order to maintain active interpersonal relationships. In particular, several studies have highlighted various difficulties in interpreting social situations (Banati, Sandor, Mike, Illes, Bors, Feldmann, Herold \& Illes, 2010), as well as deficits in theory of mind, reduced empathy levels, and alexithymia in MS patients (Kraemer, Herold, Uekermann, Kis, Daum, Wiltfang \& Abdel-Hamid, 2013; Pöttgen, Dziobek, Reh, Heesen \& Gold, 2013). Although alexithymia is personality trait independent from clinical diseases, a high rate of alexithymia has been reported in several medical conditions and physical disorders such as asthma, hypertension, chronic pain, and other physical illness (Grabe et al., 2010; Lumley, Neely \& Burger, 2007). 
Several studies that investigated the relation between alexithymia and MS provide evidence for deficits in the recognition of emotional states and emotional introspection (Prochnow et al., 2011). Data showed that emotional disorders, like alexithymia, remain stable over time in patients with MS, but emotional intelligence and alexithymia could be influenced by expressive writing and arts because of their therapeutic benefits (Holmqvist \& Lundqvist, 2012).

The international literature agrees upon the need to modulate the traditional psychoanalytic setting in the direction of refocusing on the body and organic symptoms, which tend to hinder the processes of imagination and symbolic processing, in order to achieve a greater capacity to verbalize bodily sensations and emotional experiences (Bucci, 1997). In a complex and delicate setting like that of neurological rehabilitation, patients who struggle to express their emotions verbally can find a new form of communication, featuring sounds and images, through expressive therapies applied within group settings. In a group, every patient can experience himself/herself differently through discussion and reflection with other group members; group psychotherapy is one of the methods which can decrease the behavioral, emotional, and social problems of MS patients and improve their rehabilitation. Group discussion helps patients overcome adverse feelings, behaviors, and thoughts and guides them to move toward a meaningful life. It also can improve patients' quality of life and mental health (Mazaheri, Fanian \& Zargham-Boroujeni, 2011).

Art-related materials provide a means of additional or alternative communication to words, and artistic productions are very important in understanding the group as a whole. Art has a deep bond with mind, body, and spirit; by engaging in art, one can explore, express, and address the issues related to these three areas (Malchiodi, 2009).

The review of scientific literature concerning these themes shows that the growing use of expressive therapies in this area has a positive effect on patients; among its benefits are pain reduction, mood improvements, expression of deep emotions, promotion of better communication, and improvement of patients' quality of life (Nainis, Paice, Ratner, Wirth, Lai \& Shott, 2006; Sabo \& Michael, 1996; Sahler, Hunter \& Liesveld, 2003; Zimmerman, Pozehl, Duncan \& Schmitz, 1989). Many of these authors used tools for manipulating the body that were aimed at introducing or raising awareness of processes and techniques through bodily sensations, as well as objects that function as "self-objects" whose goal is to reduce the mind-body split and thus bridge self-regulation and mentalization deficits.

The imaginative dimension is considered a fundamental survival resource, prior to the illness; after the development of MS, deficits therein can disrupt patients' reality. Imagination and creativity are powerful transformational tools that can act on the patient's mode of interpreting reality, thus gradually transforming it.

The basic assumption is that human beings have innate and potential skills: an ancient wisdom that, by re-emerging, leads to transformation. Therefore, belief in human potential means believing in the principles of self-regulation and in innate caring skills; this innate potential should be the key to developing what is enclosed in human culture. The globality of languages (GoL) theory aims at allowing the patient to regain his/her body as a body the patient listens to and does not use in terms of acting out, the driving force being the stimulation of creative expression (Guerra Lisi, 1990, 1992, 2006).

For this purpose, to implement GoL with the present study's participants, there will be workshops featuring all the expressive languages. Two channels were chosen for this project: the graphic/pictorial one and the verbal one, starting with the use of metaphor (Guerra Lisi, 1987). Metaphor-with its inherent mobility - enhances and promotes the dynamic and transitive aspects of individuals within a group. An idea emerged concerning the possibility of using a specific tool, such as myth (which is already culturally encoded) as a medium to further develop these processes. Unlike dreams, myths offer a vision of the imaginary that encroaches on the shared public space.

An area of creativity that can be shared by all group members is established; thanks to the possibility of looking at each other, it allows them to break free from stereotypes and establish an identity by way of discussion and exchange with each other. Myth has a metaphorical relationship with the difficulties to be faced, and it manages to evade the subject's conscious intentionality (Bleandonu, 1999; Romano, 2002; Siracusano, 2000) without presenting a clear, rational connection to the problem. Metaphors allow the patient's resistance to change to be bypassed; they are an indirect way of suggesting approaches and solutions to deep-seated problems.

These theoretical premises lead us to include the use of metaphors and myth in group work that is conducted in a particularly difficult context such as that of a degenerative disease, i.e., MS. In particular, we considered the way in which producing mythological tales, the so-called mythopoeic function, is closely connected to humans' psychic health and also the extent to which it offers the chance to investigate the relationship between the individual's external and internal reality (Petrella, 1985; Romano, 2002). This caused us to choose to use the myth of Ariadne and the image of the labyrinth linked to it. This myth is not only part of the history of culture and, like all the symbols that are still alive, eludes definitions and reductions; but also, thanks to its narrative apparatus, conjures up a transformative growth that does not take place through regressive adagios, but by way of a 'going forward.' One does 
not return from the labyrinth without experiencing change; one comes out of it transformed (Corrao, 1998; Neri, 1990).

\section{Aim}

This research concerns the observation of various parameters within a therapeutic group formed by patients affected by MS and recruited at IRCCS San Camillo Hospital in Venice. The groups were led by a psychologist/psychotherapist and an arts therapist, who used a psychodynamic approach to conduct the group. The clinical goal was to help individuals admitted to a neurological rehabilitation center to recognize and express their emotions, starting with their personal processing of myth. The purposes of the research are (1) to evaluate the extent to which the degrees of alexithymia changed in patients attending group treatment that featured expressive-narrative workshops and (2) to assess the change in atmosphere and therapeutic factors.

\section{Method}

\section{Participants}

Participants in this study were patients affected by MS who had been admitted to IRCCS San Camillo Hospital for intensive rehabilitation. An individual interview with the recruited patients was carried out to assess the possibility of an effective integration in the project: Only a limited number of participants with sufficiently preserved cognitive abilities (language, memory, attention), but with various degrees of motor impairment, could join the project. At the present moment, four groups have completed the therapeutic project. Each group was composed of a minimum of four and a maximum of eight patients. The final group considered for this paper consisted of eight patients affected by MS, aged between 50 and 60 years $(M=58.8 ; \mathrm{SD}=8.3)$.

As far as their family situation is concerned, all group members are married, and three of them have children. As for their education, four members hold a high school diploma and the other four members hold a middle school diploma.

The patients received their MS diagnosis from 21 to 29 years ago (mean time of MS diagnosis $=27$ years ago; $\mathrm{SD}=15.4$ ). After diagnosis, the work situation worsened for all patients because they had to suspend their professional activities as their disease progressed. Treatment was provided by a physician who was recruited to identify the patients' rehabilitation needs; the team also deemed it appropriate to suggest that the patients take part in a support group.

\section{Therapeutic Stance}

The project lasted one year, followed by six groups lasting one month each. Eight meetings, lasting one hour each, on a biweekly basis, were scheduled and were structured as follows:

1. Meeting 1: introduction of the group members, presentation of work, and explanation of objectives;

2. Meeting 2: reading of the myth of Ariadne and the use of visual and written material to memorize the myth;

3. Meeting 3: in-depth discussion on various elements of the myth (free association);

4. Meeting 4: collage workshop: everyone builds his/her own labyrinth;

5. Meeting 5: participants comment on each other's work;

6. Meeting 6: the group members are asked to describe the monster, and then to write about a labyrinthine situation they have experienced and how they managed to overcome it;

7. Meeting 7: discussion of the labyrinthine situation and comparison of the different strategies;

8. Meeting 8: review and leave-taking.

The graphic/pictorial workshop was proposed after reading the myth. It was a collage and oil pastel workshop.

Each individual was asked to freely represent his/her own personal labyrinth. It was clarified that the works produced were not going to be subject to qualitative assessment by the group leaders and that the activity did not require any artistic skill. Participants were required to give free rein to their expression, intuition, and personal choice. It was specified that the proposed materials could be used in any way: cut, torn, creased, superimposed, etc., and that there was no limit to their use.

The works were executed on neutral colored paper: Light beige or ivory are soothing colors because they are related to skin color. Containing a small amount of black, they belong to the category of grey, so they are not pure colors; therefore, they metaphorically fall into the category of "possibility."

The use of oil pastels was proposed based upon the belief that "drawing" requires "usual" gestures: All participants drew something or at least made sketches on a sheet. This technique is "less challenging" and allowed them to be welcomed into the creative dimension with kindness, breaking down some initial resistance. Moreover, the softness and smoothness of oil pastels automatically encourages movement (Guerra Lisi, 2006).

The creative moment of the workshop was light, cheerful, friendly, and, at the same time, intense. At the end of the workshop, the broken fragments gave way to complete works. Therefore, what began as an hour's worth of confusion turned into order and, finally, into expressive communication.

The second and third workshops were the narrative medicine workshops. The second workshop consisted of the patients' personal written descriptions of "the 
monster." The third one was aimed at reconstructing, through written narration, a "labyrinthine" situation, real or purely invented, and describing the manner in which patients managed to overcome it (Bert, 2003, 2007; Charon, 2001; Zannini, 2008).

\section{Measures}

Before the beginning of the treatment (T0), the Symptom Check List 90-Revised (SCL-90-R; Derogatis, 1994) was administered as a diagnostic framework in order to establish a clear picture of the main symptoms shared by the patients in the group. The Toronto Alexithymia Scale (TAS-20; Bagby, Parker \& Taylor, 1994) was administered as an outcome measure prior to the first meeting (T0) and at the end of the last meeting (T3). To evaluate the group process, Specific and Non-Specific Therapeutic Factors in Group Therapies (FAT.A.S.-G.; Marogna, Mannarini, Caccamo, Melai \& Romagnoli, 2011) and the Climate Group Questionnaire (CGQ; MacKenzie, 1981) were administered at the end of three meetings, particularly meeting 1 (T1), meeting 4 (T2), and meeting 8 (T3), respectively, to measure specific and aspecific therapeutic factors in group therapies and group affective climate.

Symptom Check List 90-Revised. The Symptom Check List 90-Revised (SCL-90-R; Derogatis, 1994) is a self-administered scale that provides a standardized measure of the current psychological and/or psychopathological state of an individual. It is composed of 90 items: Each item is assigned a score on a 5-point Likert scale, where the subject provides an assessment from 0 (not at all) to 4 (very much) relating to any symptom experienced in the previous week, until the day of the assessment. The answers provided by the subject are interpreted depending on nine symptom dimensions: somatization (SOM), obsessiveness-compulsi-veness $(\mathrm{O}-\mathrm{C})$, interpersonal sensitivity (I-S), depression (DEP), anxiety (ANX), hostility (HOS), phobic anxiety (PHOB), paranoid ideation (PAR), and psychoticism (PSY). In addition to the scores relating to specific symptom dimensions, it is also possible to calculate three global indexes that serve as indicators of symptom severity and psychological distress, and the test can also be used to measure the intensity and depth of the individual psychological distress. These three global indexes include, firstly, the Global Severity Index (GSI), which integrates information regarding the number of symptoms reported and the intensity of the perceived discomfort; the cut-off score is mean scores greater or equal to 1 . The second index is the Positive Symptom Total (PST), which is a measure of the response style and indicates whether the respondent has accentuated or minimized his/her symptoms of discomfort. Finally, the Positive Symptom Distress Index (PSDI) reflects the number of symptoms reported by the subject, regardless of the degree of discomfort associated with them.

Toronto Alexithymia Scale. The Toronto Alexithymia Scale (TAS-20; Bagby, Parker \& Taylor, 1994) scale is a self-report questionnaire that consists of 20 items investigating subjects' alexithymic areas. It requires answers on a 5-point Likert scale.

When evaluating data, as well as information relating to the total sum of the single-item scores, one can calculate the scores that refer to the items of the three dimensions that define the construct of alexithymia:

1. Difficulty in identifying feelings (Factor 1 ): items 1, 3, 6, 7, 9, 13, 14;

2. Difficulty in communicating feelings to others (Factor 2): items 2, 4, 11, 12, 17;

3 . Outside-oriented thinking (working thinking) (Factor 3): items 5, 8, 10, 15, 16, 18, 19, 20.

In accordance with the recommendations of the authors of the scale, a cut-off score of 61 is considered to delineate alexithymic cases.

Climate Group Questionnaire. The Climate Group Questionnaire (CGQ; MacKenzie, 1981) is based on the assumption that the climate or the psychological environment of the group can be explained by the perception of its members through a number of constructs. CGQ is a self-report questionnaire composed of 12 items with a 7-point Likert scale, which constitute three sub-scales relating to the level of commitment, conflict, and avoidance of responsibility for the group work.

The scoring procedure is the sum of the scores of the items for each sub-scale:

1. Involvement and cohesion indicator (items $1,2,4,8,11)$;

2. Conflict, anger, and rejection indicator (items 6, 7, 10, 12);

3. Avoidance; reluctance to address issues (items 3, 5, 9).

The potential for the clinical application of this easy-to-use tool is wide ranging and generally related to the possibility of describing the tendency of a group therapy process, the climate that characterizes its different stages of development, and the ability to show objectively whether the preconditions for the therapeutic factors necessary to achieve the change have been created.

Specific and Non-Specific Therapeutic Factors in Group Therapies. The Specific and NonSpecific Therapeutic Factors in Group Therapies (FAT.A.S.-G.; Marogna, Mannarini, Caccamo, Melai \& Romagnoli, 2011) questionnaire is used to investigate the specific and non-specific factors of group psychotherapy. This tool comes from re- 
search conducted at the Laboratories of Research and Applied Psychology of the University of Padua (L.I.R.I.P.A.C.) by Dr. Cristina Marogna (Marogna et al., 2011). It was built from the existing literature on therapeutic group factors and on the most recent related research, taking into account many authors such as Yalom (1997) and MacKenzie (2002) and some tools like GrEThA-Q (Giorgi, Sguazzin, Baiardi, Simone \& Tesio, 2006) and CGQ (MacKenzie, 1981) that investigated the therapeutic experience in groups. The FAT.A.S.-G. is a 41 -item questionnaire and features two different versions: one for the patients and one for the therapist (and possibly for the co-therapist and other professionals participating in the sessions). The questions for the patients are mainly related to how they feel in a group, what their personal contribution to the group is, and how useful they believe it is to participate in it. In parallel, the therapists are asked to assess the group according to the same aspects. Items are grouped into the following ten factors: hope infusion, universality, altruism, interpersonal learning, recapitulation, cohesion, catharsis, imitative behavior, guide, and existential factors. The score of each factor is calculated as the average score of the items belonging to each factor. The factors of FAT.A.S-G. are evaluated on a Likert scale from 0 to 4, where higher scores reflect a greater presence of therapeutic factors, as perceived in both clinicians and patients. The tool grants a better understanding of the group process, thanks to the observation of the scores of the therapeutic factors. FAT.A.S-G. aimed at analyzing the group therapeutic process identifying the way in which nonspecific and specific therapeutic factors develop and how they are modified. Starting from the analysis of the group process, Yalom (1995) maintains that the therapeutic change is due to a process that develops through an intricate interaction of human experiences, represented by the therapeutic factors. The author identifies eleven therapeutic factors and underlines that the distinctions among said factors are arbitrary. The factors appear to be interrelated, and none of them appears or functions separately; they may constitute different parts of the change process. From the clinical point of view, it is interesting to focus on a particular aspect of the therapeutic change: It is possible to break up the therapeutic change into specific and non-specific factors.

The non-specific therapeutic factors are those aspects that do not depend on the theoretical model or on the specific technique used by the therapist but rather on the fact itself of having provided the patient with a physical and mental space where he/she can bring his/her pain. These non-specific factors allow for the emergence of a powerful virtuous circle, which is essential for the treatment, even when they represent the ground for the use of the specific techniques of a theory. Finally, the "specific therapeutic factors" contribute to the therapeutic change and are related to a specific theoretical therapeutic model and the strategies derived from it.

\section{Statistical Analysis}

For the statistical analysis, Statistical Package for Social Sciences (SPSS 21.00) was used. Given the paucity of the sample size, nonparametric measures for data analysis were used, i.e. the Friedman test and the Wilcoxon test, to evaluate differences among group means at $\mathrm{T} 1, \mathrm{~T} 2$, and $\mathrm{T} 3$; moreover, these statistics were used to evaluate significant changes in the measure of the outcome.

\section{Results}

The SCL-90-R scale was administered before the group treatment to collect information to identify the prevalent symptoms among the patients in the group. Patients reached values over $\mathrm{T}=60$ on the somatization scale ( $\mathrm{SOM}$ ), interpersonal sensitivity scale (I-S), and depression scale (DEP). These results describe the defensive response of patients with a degenerative disease. The symptoms, mainly somatization and depression, can be an emotional manifestation of a disease experienced almost entirely in the body.

With regard to TAS-20, results of nonparametric statistics did not show significant changes, but with respect to the cut-off scores $(\geq 61=$ positive alexithymia; $50-60=$ indeterminate alexithymia; $50=$ negative alexithymia), it is possible to determine that the average degree of alexithymia decreased following treatment (Table 1 and Figure 1). This decrease shows us that patients improved both in their capacity of expressing and acknowledging their own feelings and in the ability to express themselves and feel accepted by the group. Group activities facilitated the opportunity to talk about the disease in all its aspects without fear. The ability to recognize emotions from time to time during the meetings increased members' capacity to observe their own and others' emotions. Particularly, we observed a decrease at T2 in the score of Factor 2, which indicates a lower difficulty for patients in communicating their emotional experiences to others. With regard to CGQ, Friedman test results did not show significant changes, although, from a qualitative viewpoint, some changes may be observed (Figure 2). Initially, the treatment group showed obvious difficulties in relating to each other and opening up; over time, meeting after meeting, the group participants were able to develop good empathy and familiarity. Particularly, the involvement factor slightly decreased at time T2 $(M=3.4)$ (theme of the drawing workshop) with respect to time $\mathrm{T} 1(\mathrm{M}=3.6)$ (theme of respect), and increased again to reach its peak by time T3 $(M=4.5)$, corre- 
Table 1. Descriptive statistics for SCL-90R, CGQ, TAS-20 and FAT.A.S-G. in T0, T1, T2 and T3

\begin{tabular}{|c|c|c|c|c|c|c|}
\hline & $\begin{array}{c}\text { T0 } \\
M ; S D\end{array}$ & $\begin{array}{c}\mathrm{T} 1 \\
M ; S D\end{array}$ & $\begin{array}{c}\mathrm{T} 2 \\
M ; S D\end{array}$ & $\begin{array}{c}\text { T3 } \\
M ; S D\end{array}$ & $\begin{array}{c}\text { Friedman } \\
\text { Test }\end{array}$ & Sign. \\
\hline \multicolumn{7}{|l|}{ SCL-90R } \\
\hline Somatisation & $1.68 ; 0.39$ & & & & & \\
\hline $\begin{array}{l}\text { Obsessiveness- } \\
\text { compulsiveness }\end{array}$ & $1.18 ; 0.92$ & & & & & \\
\hline Interpersonal sensitivity & $1.30 ; 0.97$ & & & & & \\
\hline Depression & $1.26 ; 0.67$ & & & & & \\
\hline Anxiety & $0.92 ; 0.72$ & & & & & \\
\hline Hostility & $1.05 ; 0.95$ & & & & & \\
\hline Phobic anxiety & $0.67 ; 0.60$ & & & & & \\
\hline Paranoid ideation & $1.13 ; 0.80$ & & & & & \\
\hline Psychoticism & $1.01 ; 0.86$ & & & & & \\
\hline Sleep & $1.28 ; 0.61$ & & & & & \\
\hline Global Severity Index (GSI) & $1.16 ; 0.66$ & & & & & \\
\hline \multicolumn{7}{|l|}{ CGQ } \\
\hline Involvement & & $3.6 ; 0.89$ & $3.4 ; 0.81$ & $4.5 ; 1.07$ & 4.05 & .10 \\
\hline Conflict & & $0.5 ; 0.12$ & $0.2 ; 0.07$ & $0.5 ; 0.14$ & 2.53 & .28 \\
\hline Avoidance & & $2.1 ; 0.82$ & $1.5 ; 0.83$ & $1.7 ; 1.14$ & 0.13 & .93 \\
\hline \multicolumn{7}{|l|}{ TAS-20 } \\
\hline $\begin{array}{l}\text { Difficulty in identifying feel- } \\
\text { ings }\end{array}$ & $23.3 ; 21.4$ & & & $19 ; 18.2$ & 4.06 & .91 \\
\hline $\begin{array}{l}\text { Difficulty in communicating } \\
\text { feelings to others }\end{array}$ & $18 ; 15.6$ & & & $13.3 ; 11.9$ & 1.02 & .31 \\
\hline Outside-oriented thinking & $24 ; 22.8$ & & & $18.3 ; 16.7$ & 3.76 & .86 \\
\hline \multicolumn{7}{|l|}{ FAT.A.S.-G. } \\
\hline Altruism & & $2.25 ; 1.92$ & $2.83 ; 1.88$ & $3.06 ; 2.31$ & 0.66 & .71 \\
\hline Interpersonal Learning & & $1.22 ; 1.03$ & $1.33 ; 1.02$ & $2.00 ; 1.86$ & 2.01 & .37 \\
\hline Catharsis & & $2.25 ; 2.08$ & $2.42 ; 1.88$ & $2.75 ; 2.31$ & 2,67 & .26 \\
\hline Cohesion & & $2.58 ; 2.43$ & $2.33 ; 1.91$ & $2.94 ; 2.71$ & 5.63 & .05 \\
\hline Imitative Behaviour & & $2.50 ; 2.41$ & $1.67 ; 1.54$ & $2.88 ; 2.42$ & 4.21 & .084 \\
\hline Factors Existential & & $2.75 ; 2.69$ & $2.25 ; 2.11$ & $2.88 ; 1.96$ & 4,67 & .096 \\
\hline Information-guide & & $2.53 ; 2.33$ & $2.67 ; 2.25$ & $3.25 ; 2.91$ & 4,91 & .086 \\
\hline Hope Infusion & & $3.00 ; 2.06$ & $3.08 ; 2.81$ & $3.56 ; 3.03$ & 6.06 & .05 \\
\hline Recapitulation & & $1.08 ; 0.76$ & $1.42 ; 1.38$ & $1.94 ; 1.52$ & 2.66 & .27 \\
\hline Universality & & $2.50 ; 1.85$ & $2.25 ; 2.10$ & $3.25 ; 3.08$ & 4.02 & .13 \\
\hline
\end{tabular}

sponding to the last meeting of the group. The patients had already established a good relationship, and the topics covered were all positive. The conflict factor remained unchanged over time and consistently at low levels. During the workshops, intense themes emerged, at times tinged with aggression, but patients handled them with growing confidence as they were mediated by the workshops.

Finally, the avoidance factor reached its peak at time $\mathrm{T} 1(\mathrm{M}=2.1)$, decreased at time $\mathrm{T} 2(\mathrm{M}=1.5)$ when the highest level of cohesion and dialogue among patients was recorded, then slightly increased at time T3 $(\mathrm{M}=1.7)$, presumably as a de- fense against feelings of regret and abandonment connected to the end of the group treatment.

With regard to FAT.A.S.-G., we observed that, at time T3, the average of each factor increased if compared to all the averages of $\mathrm{T} 1$ and $\mathrm{T} 2$ times (Figure 3).

The Friedman test proved to be significant for the cohesion factor $\left(\mathrm{X}^{2}=5.63, \mathrm{df}=2, \mathrm{p}<.05\right)$. The next Wilcoxon test showed that significant differences existed between T2 and T3 $(\mathrm{z}=-1.82$, $\mathrm{p}$ $<.05)$. In addition, the Friedman test was found significant for the hope infusion factor $\left(\mathrm{X}^{2}=6.6, \mathrm{df}\right.$ $=2, \mathrm{p}<.050$ ), and the Wilcoxon test showed differ- 
TAS-20

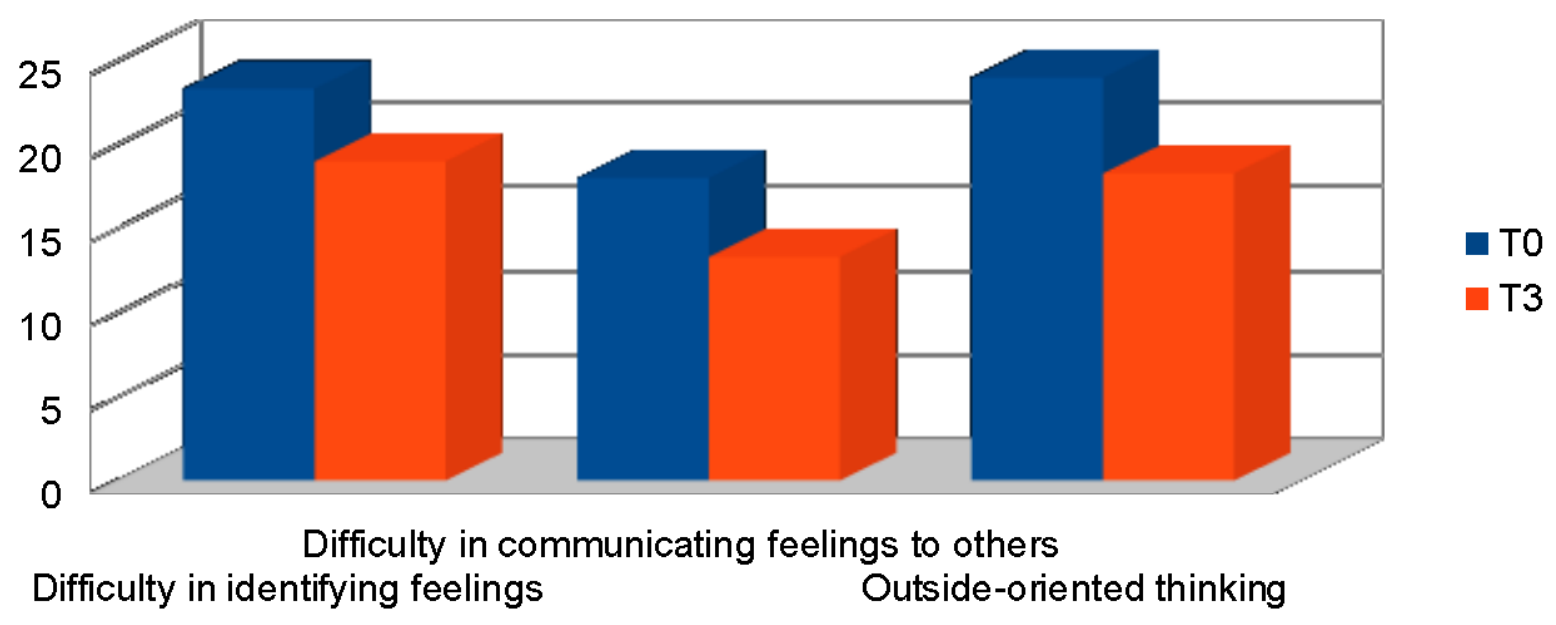

Figure 1. Mean scores of TAS-20 factors at T0 and T3.

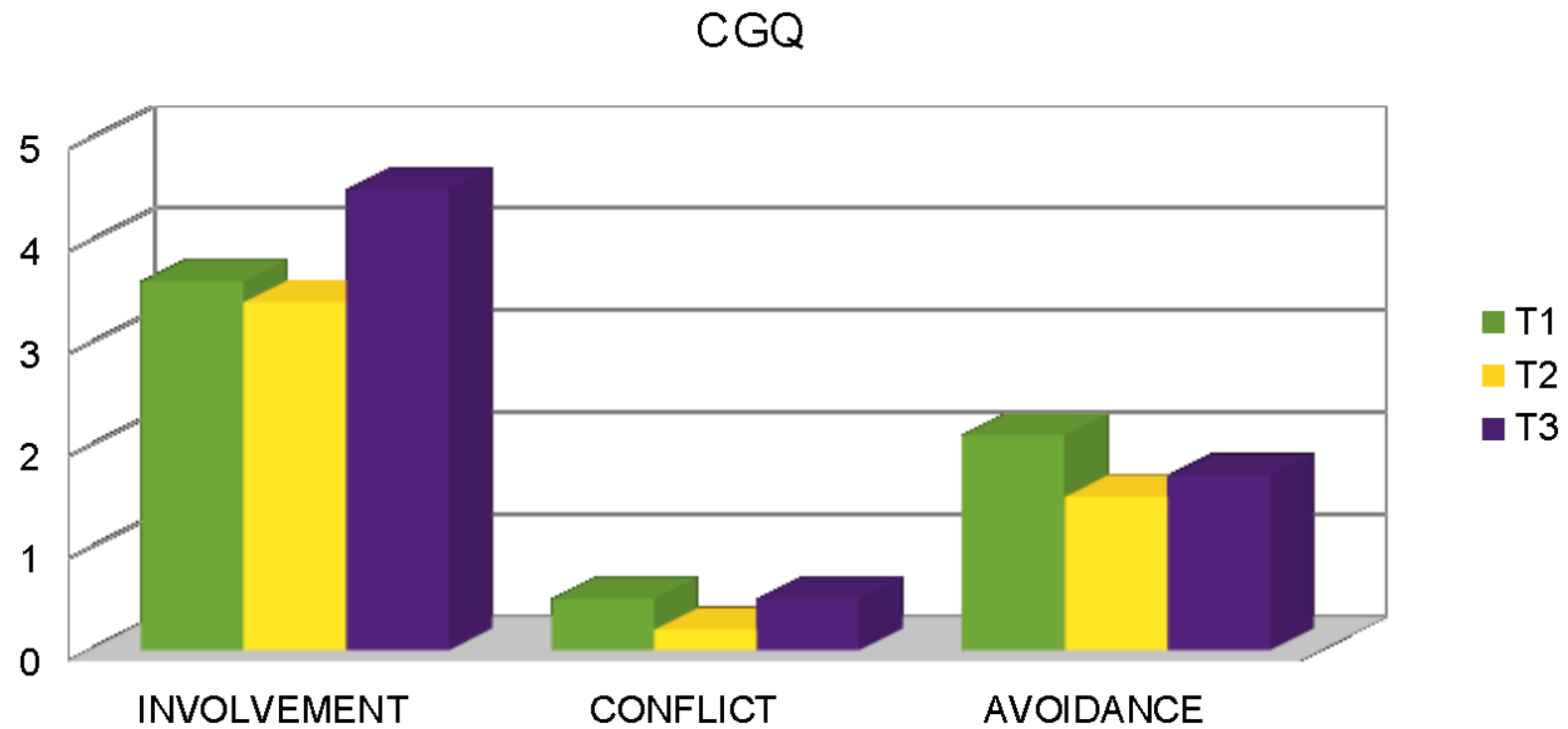

Figure 2. Mean scores of CGQ scales at T1, T2 and T3.

ences between $\mathrm{T} 1$ and $\mathrm{T} 2(\mathrm{z}=-1.84, \mathrm{p}<.05)$.

The significant increase in the hope infusion factor is expressed through the ability to address the issue of the future and the consequences of the disease over the years, something previously considered taboo. Initially, fear of the evolution of the disease and the resulting disability stimulated a deep and almost unbearable anguish, but later on it lead to questioning the meaning of one's own existence and the need to find a meaning to life (Crotti, Di Leo \& Viterbori, 1998). Also, an increase in the altruism factor was noted, which was brought into the group as an opportunity for mutual help.

\section{Discussion}

Patients with MS appear to have a higher prevalence of a number of psychological symptoms and disorders, such as depression and anxiety, affecting their quality of life (Chwastiak \& Dawn, 2007). Moreover, a fragile sense of the self, a weakening of the ego capacities to fulfill its own duties, and a use of primitive defense mechanisms can be found in these patients (Lorio, Moressa, Meneghello, Salcuni, Stabile, Zennaro, Ferro \& Tonini, 2010). Other emotional disturbances have been reported in patients with MS, such as pathological laughing and 
FATAS-G.

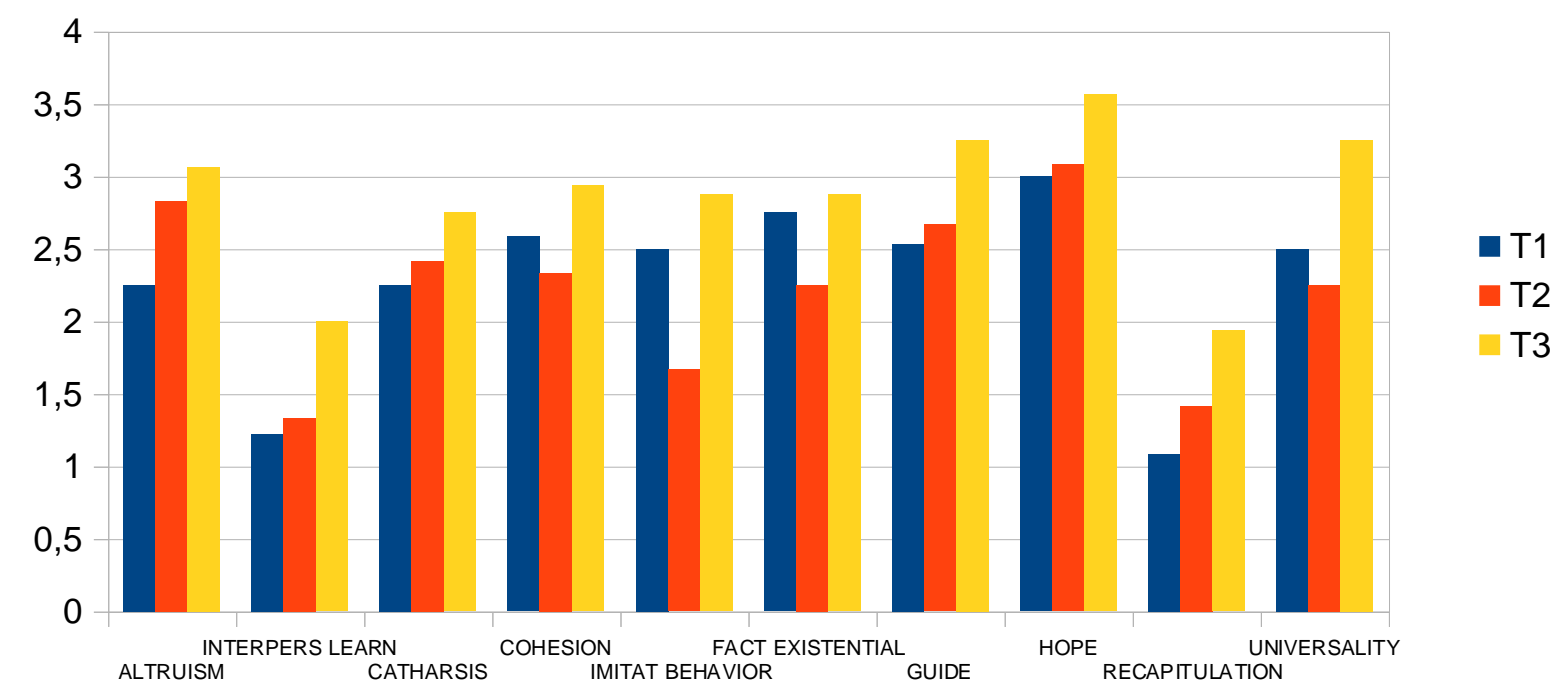

Figure 3. Mean scores of FAT.A.S.-G. factors at T1, T2 and T3.

crying, emotional weakness, and alexithymia features (Montel \& Bungener, 2007; Montreuil \& Petropoulou, 2003).

The aim of this work was to analyze how a group therapy treatment, integrated with an intervention of art therapy, can promote the understanding of the way illness is experienced and a different perception of the self in patients with MS. For this reason, we used the myth of Ariadne and the image of the labyrinth, which is part of the history of culture and-like all symbols that are still alive-elude definitions and reductions.

The review of scientific literature concerning these themes shows that the growing use of expressive therapies in this area has a positive effect on patients, and among the benefits are mood improvements, expression of deep emotions, and promotion of a better communication (Nainis et al., 2006).

The first aim of this research was to evaluate the extent to which the degree of alexithymia changes in patients attending a group treatment with expressive-narrative workshops. Unfortunately, analysis did not reveal significant statistical results, but qualitatively, it is possible to observe a decrease in the score of Factor 2, which is equivalent to a lower difficulty of communicating their feelings to each other. Myths and their narration, within a group setting, appear to us as possible resources that can promote mental transformation processes and act as a bridge between different levels of reality, internal and external. In this research group, patients demonstrated an increased capacity to identify and express their emotions and share them with others; this ability could be due to the group process that promotes emotional closeness among members in relation to the disease.
The second aim of the study was to assess the change in atmosphere and therapeutic factors.

The presence of the group enables the enhancement of patients' personal characteristics, which are no longer related to physical existence. This also increases self-observation and the possibility of considering oneself a person in one's own psychophysical complexity. From the analysis of the climate of the group, no statistically significant results emerged. From the qualitative point of view, we can observe that the mean score of the involvement increases over time. The relationships that developed among the members allowed the group meetings to become a space in which to perform an exchange of mutual aid, which facilitated self-awareness, change, and support. Group therapy therefore acts as a catalyst for creating dynamic relational experiences and motivational support, capable of contributing to the creation of an environment conducive to change.

The only statistically significant results emerged from FAT.A.S.-G., a not yet validated tool. Particularly, the two therapeutic factors that increased over time are cohesion and hope infusion. The increased cohesion allowed group participants to increase their level of self-awareness; in these conditions of acceptance and understanding, patients were willing to express and explore themselves and to become aware of and integrate previously unacceptable aspects. For the duration of the group experience, it was, in fact, possible to express anger about one's own disease. This safe and accepting context facilitated the development of catharsis, the revelation of intimate and personal facts, but especially the free expression of patients' negative feelings.

Through the collage workshop and the discussion 
of one's own labyrinth, it was possible to improve the ability to produce mythological stories, the socalled mythopoeic function that is a critical function for human beings' mental health (Petrella 1985; Romano, 2002). Thus, the group setting, the myths, and their narration co-created an emotional state in which 'sclerosing' notes were able to become dynamic again, despite the fears, and more voices could be heard, going through more levels of reality, thus creating the depth which is needed for thought. This does not mean that fears have disappeared, but quite the opposite: Perhaps the group work enhanced them; at the same time, however, it gave the opportunity to name them and bring them back into a framework of cohesion and deep understanding.

The present study has some limitations. First, the sample size is too small to be considered a representative sample of the population of MS patients. In addition, to evaluate the therapeutic factors FAT.A.S.-G., a questionnaire not yet validated, was used, which is the only instrument that highlights significant results, but it is also the only tool that does not have consistent data on reliability. Finally, the administration of the SCL-90-R was not carried out at the end of the treatment (T3), and this represents a lack of an outcome measurement that makes it difficult to discuss any changes in the symptomatology of the patients.

In the future, it will be necessary to improve the system of statistical research, using outcome measures both at the beginning and at the end of treatment. In addition, it could perform the analysis of correlation between the outcome and process instruments to assess how the therapeutic process of the group influences the change of the patients.

\section{References}

Bagby, R. M., Taylor, G. J. \& Parker, J. D. A. (1994). The Twenty-Item Toronto Alexithymia Scale-II: Convergent, discriminant, and concurrent validity. Journal of Psychosomatic Research, 38, 33-40. doi: 10.1016/00223999(94)90005-1

Banati, M., Sandor, J., Mike, A., Illes, E., Bors, L., Feldmann, A., Herold, R. \& Illes, Z. (2010). Social cognition and theory of mind in patients with relapsing-remitting multiple sclerosis. European Journal of Neurology, 17(3), 426433. doi: $10.1111 /$ j.1468-1331.2009.02836

Bert, G. (2003). Parole di medici, parole di pazienti: counselling e narrativa in medicina. Il Pensiero Scientifico Editore. [Words of doctors, patients words: counseling and narrative in medicine]. Roma: Il Pensiero Scientifico Editore.

Bert, G. (2007). Medicina narrativa: Storie e parole nella relazione di cura. [Narrative medicine: Stories and words in the care relationship]. Roma: Il Pensiero Scientifico Editore.

Bleandonu, G. (1999). L'analisi dei sogni e lo sguardo mentale. [Dream analysis and gaze mental]. Roma: Borla.

Bucci, W. (1997). Psychoanalysis and cognitive science. New York: The Guilford Press.

Buelow, J. M. (1991). A correlational study of disabilities, stressors, and coping methods in victims of multiple sclerosis. The Journal of Neuroscience Nursing, 23(4), 247-
252. doi: 10.1097/01376517-199108000-00012

Chalk, H. M. (2007). Mind over matter: Cognitivebehavioral determinants of emotional distress in multiple sclerosis patients. Psychology, Health, and Medicine, 12(5), 556-566. doi: 10.1080/13548500701244965

Charon, R. (2001). Narrative medicine. A model for empathy, reflection, profession, and trust. Chicago, IL: American Medical Association.

Chwastiak, L. A. \& Dawn, M. D. (2007). Psychiatric issues in multiple sclerosis. Psychiatric Clinics of North America, 30 (4), 803-817. doi: 10.1016/j.psc.2007.07.003

Corrao, F. (1998). Orme. Volume 1. [Footsteps Volume 1]. Milano: Adelphi.

Counte, M. A., Bieliauskas, L. A. \& Pavlou, M. (1983). Stress and personal attitudes in chronic illness. Archives of Physical Medicine and Rehabilitation, 64(6), 272-275. PMID: 6860098

Crotti, N., Di Leo, S. \& Viterbori, P. (1998). Dalla paura al cambiamento. In Crotti N. (a cura di) Cancro: percorsi di cura (pp. 41-555). [From fear to change. In Crotti N. (Ed.) Cancer: care pathways]. Roma: Meltemi.

Derogatis, L. R. (1994). Symptom Check List 90-R: Administration, scoring, and procedures manual (3rd ed.). Minneapolis, MN: National Computer Systems.

Giorgi, I., Sguazzin, C., Baiardi, P., Simone, A. \& Tesio, L. (2006). Uno strumento per la valutazione dell'attività terapeutica di gruppo (GrEThA-Q). [A tool for the evaluation of therapeutic group (GrEThA-Q)]. Giornale Italiano di Medicina del Lavoro ed Ergonomia, 28 (1), Supplemento Psicologia 1, 61-70. doi: 10.13140/2.1.1779.0409

Grabe, H. J., Schwahn, C., Barnow, S., Spitzer, C., John, U., Freyberger, H. J., Schminke, U., Felix, S. \& Volzke, H. (2010). Alexithymia, hypertension, and subclinical atherosclerosis in the general population. Journal of Psychosomatic Research, 68, 139-147. doi: 10.1016/j.jpsychores.2009.07.015.

Guerra Lisi, S. (1987). Il metodo della globalità dei linguaggi. [The method of the totality of languages]. Roma: Borla.

Guerra Lisi, S. (1990). Come non spezzare il filo. [How not to break the thread]. Roma: Borla.

Guerra Lisi, S. (1992). Il racconto del corpo. [The tale of the body]. Roma: Borla.

Guerra Lisi, S. (2006). La trans-formazione possibile nella globalità dei linguaggi. Metodi di interazione. [Transformation possibilities in the totality of languages. Methods of interaction]. Pisa: Ed. Del Cerro.

Holmqvist, G. \& Lundqvist C. (2012). Is there evidence for the use of art therapy in treatment of psychosomatic disorders, eating disorders and crisis? A comparative study of two different systems for evaluation. Scandinavian Journal of Psychology, 53(1), 47-53. doi: $10.1111 / \mathrm{j} .1467-9450.2011 .00923$

Korostil, M. \& Feinstein, A. (2007). Anxiety disorders and their clinical correlates in multiple sclerosis patients. $\mathrm{Mul}$ tiple Sclerosis, 13(1), 67-72. doi: $10.1177 / 1352458506071161$

Kraemer, M., Herold, M., Uekermann, J., Kis, B., Wiltfang, J., Daum, I., Dziobek, I., Berlit, P., Diehl, R. R. \& AbdelHamid, M. (2013). Theory of mind and empathy in patients at an early stage of relapsing remitting multiple sclerosis. Clinical Neurology and Neurosurgery, 115(7), 1016-1022. doi: 10.1016/j.clineuro.2012.10.027

Lorio, R., Moressa, G., Meneghello, F., Salcuni, S., Stabile, M. R., Zennaro, A., Ferro, L. \& Tonini, P. (2010). Personality functioning in patients with a progressive course of multiple sclerosis. Psychological Reports, 107 (2), 629-646. doi: 10.2466/02.09.15.19.PR0.107.5.629-646

Lumley, M. A., Neely, L. C. \& Burger, A. J. (2007). The assessment of alexithymia in medical settings: Implications 
for understanding and treating health problems. Journal of Personality Assessment, 89, 230-246. doi: $10.1080 / 00223890701629698$

MacKenzie, K. R. (1981). Measurement of group climate. International Journal of Group Psychotherapy, 31, 287295. PMID-7263113

MacKenzie, K. R. (2002). Psicoterapia breve di gruppo. [Time-Managed Group Psychotherapy: Effective Clinical Application]. Trento: Ed. Erickson.

Malchiodi, C. (2009). Arteterapia, l'arte che cura. [Art therapy, art that cares]. Firenze: Giunti Edizioni.

Marogna C., Mannarini S., Caccamo F., Melai C. \& Romagnoli L. (2011) I fattori terapeutici in psicoterapia breve di gruppo: un primo contributo nella definizione di una misura: La ricerca empirica in terapia psicodinamica di gruppo. [The therapeutic factors in brief psychotherapy group: a first contribution in the definition of a measure: Empirical research in psychodynamic therapy group]. Quaderno CRS Coirag, 16, 155-167.

Mazaheri, M., Nasrin Fanian, M. A. \& Zargham-Boroujeni, A. (2011). Experiences of patients with multiple sclerosis from group counseling. Iranian Journal of Nursing and Midwifery Research, 16(2), 181-190. PMCID: PMC3249770

Montel, S. \& Bungener, C. (2007). Mood and emotional disorders in multiple sclerosis: A literature review. Review of Neurological Diseases, 163, 27-37. doi: 101019-200603491

Montreuil, M. \& Petropoulou, H. (2003). Emotional disturbances in neurology and psychiatry: Mood and emotions in multiple sclerosis. Neuropsychological News, 2, 91-96.

Nainis, N., Paice, J. A., Ratner, J., Wirth, J. H., Lai, J. \& Shott, S. (2006). Relieving symptoms in cancer: Innovative use of art therapy. Journal of Pain and Symptom Management, 31(2), 162-169. doi: $10.1016 /$ j.jpainsymman.2005.07.006

Neri, C. (1990). La fusionalità. [Fusionality]. Roma: Edizione Borla.

Patten, S. B., Fridhandler, S., Beck, C. A. \& Metz, L. M. (2003). Depressive symptoms in a treated multiple sclerosis cohort. Multiple Sclerosis, 9(6), 616-620. doi: $10.1191 / 1352458503 \mathrm{~ms} 960 \mathrm{oa}$

Petrella, F. (1985). La mente come teatro. [The mind as theater]. Torino: Centro Scientifico Torinese.

Pöttgen, J., Dziobek, I., Reh, S., Heesen, C. \& Gold, S. M. (2013). Impaired social cognition in multiple sclerosis. Journal of Neurology, Neurosurgery and Psychiatry, 84(5),
523-528. doi: 10.1136/jnnp-2012-304157

Prochnow, D., Donell, J., Schäfer, R., Jörgens, S., Hartung, H. P., Franz, M.,\& Seitz, R. J. (2011). Alexithymia and impaired facial affect recognition in multiple sclerosis. Journal of Neurology, 258(9), 1683-1688. doi: 10.1007/s00415-011-6002-4.

Romano, R. (2002). Il racconto della mente, il mito nella relazione psicoanalitica. [The story of the mind, the myth in the psychoanalytic relationship]. Bari: Edizioni Dedalo.

Sabo, C. E. \& Michael, S. R. (1996). The influence of personal message with music on anxiety and side effects associated with chemotherapy. Cancer Nursing, 19(4), 283289. doi: 10.1097/00002820-199608000-00004

Sahler, O. J., Hunter, B. C. \& Liesveld, J. L. (2003). The effect of using music therapy with relaxation imagery in the management of patients undergoing bone marrow transplantation: A pilot feasibility study. Alternative Therapies in Health and Medicine, 9(6), 70-74. PMID: 14618861

Schwartz, C. \& Frohner, R. (2005). Contribution of demographic, medical, and social support variables in predicting the mental health dimension of quality of life among people with multiple sclerosis. Health and Social Work, 30(3), 203-212. PMID: 16190296

Senders, A., Wahbeh, H., Spain, R. \& Shinto, L. (2012). Mind-body medicine for multiple sclerosis: A systematic review. Autoimmune Diseases. Article ID 567324, doi:10.1155/2012/567324

Siracusano, F. (2000). Introduzione allo studio del Rito. [Introduction to the study of the Rite]. In Koinos: Gruppo e Funzione Analitica, anno XXI, n. 1.

Yalom, I. D. (1997). Teoria e pratica della psicoterapia di gruppo. [The theory and practice of group psychotherapy]. Torino: Bollati Boringhieri.

Zannini, L. (2008). Medical humanities e medicina narrativa: Nuove prospettive nella formazione dei professionisti della cura. [Medical humanities and narrative medicine: New perspectives in the training of care professionals].Torino: Raffaello Cortina.

Zimmerman, L., Pozehl, B., Duncan, K. \& Schmitz, R. (1989). Effects of music in patients who had chronic cancer pain. Western Journal of Nursing Research, 11(3), 298-309. PMID: 2750142

Submitted December 22, 2013

Revision received March 24, 2014

Accepted January 28, 2015 